out life or should the individual endeavor to overcome his or her muscular weakness? To this end I have found of the greatest value the exercises recommended by Osgood ${ }^{5}$ in a recent article, which encourage the development of good plantar muscles and good grasping function in the toes. Ten or fifteen minutes given a day to systematic use of the anterior part of the foot, and an attempt at education of the muscles which move the toes, will result in a great improvement in a short space of time. The gait will become elastic and comfortable. The excision of the head of the fourth metatarsal bone is rarely necessary and rarely done at the present time. There seems to be no reason for this operation. The question of proper shoes is one that requires very careful adjustment, as it is necessary to supply the patient with a shoe that has a broad enough toe for comfortable use and also one that makes some concessions to style.

REFERENCES.

1 T. G. Morton: Am. Jour. Med. Sc., 1876.

2 Joel E. Goldthwait: Boston MED. AND SuRa. Jour., vol. exxxi p. 233. Trans. Am. Orthop. Asso., vol. vii, 1894

W. A. Hardaway and Nathaniel Allison: Jour. Cutan. Dis.,

March, 1906. Trans. Am. Orthop. Asso., 1906.

\section{NERVE-STRAIN OF SCHOOL CHILDREN.*}

BY LOUIS W. FLANDERS, M.D., DOVER, N. H.

IN some respects the child of to-day has come into a goodly heritage. The increased knowledge on the part of medical men, the more stringent enforcement of sanitary laws and the better education of the parents with regard to the health of the child have placed him upon a much safer platform than that occupied by the child of thirty or forty years ago. But, unfortunately, with all this improvement of the child's physical condition, there is coming to be a constantly increasing demand upon his intellectual capacity, so that we are in danger of losing all we have gained by substituting in the place of former coarser ills the more insidious derangements which result from an overtaxed nervous system.

Every day brings to the oculist its proportion of child patients. It is a daily story of eyes-ache, headache, nervousness, fretfulness, lassitude, loss of appetite and troubled sleep. To all outward appearances these children are well nourished, but a closer inspection will reveal that their muscles lack the wiry hardness of the country child of forty years ago. It is a case of development of brain at the expense of brawn. Of course not all children are of this class. Many are able to endure the excessive demands made upon them without loss of health, but the proportion of neurasthenics is constantly increasing and it is a grave question whether, if the present pace is continued, we may not have a generation of nervous invalids ahead of us. Up to the age of twelve years the boy and the girl should be treated just alike physically. They are both young ani-

2* Read before the New Hampshire State Medical Society at the annual meeting of 1907 . mals and should have a few hours of study, a few hours of play and unlimited sleep. Five hours of close work is all that should be required of a child at this age, and if he idles away his time in school, the penalty should be loss of promotion and not curtailment of hours of recreation and sleep.

But are we always fair to children? The teacher says, or the parent admits, that a child does not apply himself during school hours.

When we are about to prepare a paper for these meetings, we wait until after office hours, lock the doors, and in solemn stillness, surrounded by books and papers, the labor begins which for some of us continues many weary hours before the child is born.

Contrast your environment with the environment of the child during school hours. Surrounded by a multitude of uneasy youngsters to attract his attention, amidst a babel of noisy recitations, he is expected to solve a problem in arithmetic or to commit to memory a page of geography. I have seen conscientious children with fingers stuffed in their ears and with eyes downcast to shut out alluring visions struggling with this difficult task. Mental concentration to the exclusion of all disturbing elements is greatly to be desired and cultivated, but we should not expect it in the school child.

A year or two ago a little girl, twelve years old, an inmate of a fashionable New York boardingschool (I use the word "inmate" advisedly) was brought to me for examination. There was the usual history of nervous derangement and, inasmuch as headache and eyes-ache were especially prominent, it had been suggested that eye-strain might be the cause of the trouble. Now there was absolutely nothing wrong with that child's eyes and so I began to question her about her work. I said,

"How many studies do you have?"

"Four: Arithmetic, English, spelling and geography," or something like that.

I said, "Music, of course?" Yes, she had a music lesson once a week and practised an hour a day.

"And drawing and painting?" Yes, she had a drawing lesson once a week. "And dancing?" Yes, she had a dancing lesson once a week.

Then I turned to the mother and said, "Is this all she has in the way of studies?"

"Well," the mother replied, "she is a nice little French scholar and she has an hour a week of French conversation."

"And is that all?" I persisted.

"Yes, unless you call a lesson in elocution a study."

Then turning to the little patient, I asked her how much exercise she took. She said she spent an hour in the gymnasium every forenoon. "But don't you get any out-of-door exercise?" Oh, yes, they were obliged to go to walk with the teachers for an hour and a half every pleasant afternoon.

Can't you see that walk? That little string of galley slaves with a teacher in front and one 
behind, solemnly exercising? Why, when Dr. Smith and Is were school boys, we burst out of that schoolhouse after being pent up for an hour and a half with a yell you could have heard from here to Manchester, and the chances are that we ran around that school yard about four times just to let off steam. There was no stale, residual air in our lungs and no flabby muscles on our bones.

I see students from Harvard, Yale, Tech., Dartmouth, New Hampshire College, Exeter, Andover and through the high schools down to the primary grades, and it is always the same story, - a constantly increasing scholastic standard to attain and a consequent diminution of the hours of recreation and sleep.

If we were to select 100 school children from all parts of this city, it is evident that we should have all shades of intellectual ability represented in those 100 children. It is obvious that if they are all to be graduated together year by year from a lower to a higher grade the standard for graduation should not be higher than the capacity of the weakest mind. But that would be an injustice to the intellectually bright child and so, little by little, the standard has been raised and the attempt is being made to draw the duller child up to the level of his brighter neighbor, as I believe, to the detriment of his health.

Now let us look at the forces that have produced this condition. First, the world is daily requiring more knowledge on the part of the doctor, the lawyer, the electrical engineer, the machinist, the craftsman of every sort. Recent discoveries in medicine, electricity and mechanics have so broadened the field of each that it is no longer possible to acquire a working knowledge of these sciences in the time allotted for that purpose twenty years ago. The medical student must now take four full years in a medical college. The electrical engineer has but learned the rudiments of his profession after four busy years in a technical school. Trades that were learned years ago by a system of apprenticeship now require a certain amount of scholastic training in addition, while, on the other hand, the time given us to acquire and practice all these things is still limited to fourscore years and ten.

Another force that is working to produce nervous disease in our children is the insane American desire to emulate one's neighbor. Just as people spend the last cent of their incomes in a frantic attempt to appear in the society of more prosperous friends, even so the minds of children are taxed to their utmost capacity in order that they may appear intellectually equal to their brighter neighbors. If a child does not make his grade, or if his marks are lower than his mates', some deep disgrace seems to be attached to the fact in the minds of the parents.

One of the brightest men that I ever knew, a man who read Greek for a pastime and delved in deep mathematical problems for relaxation, a man who throughout his college course was a source of terror to his professors on account of the breadth and exactness of his knowledge, turned out to be of absolutely no use in the busy world.
He has never retained a position more than a year at a time since he graduated, while, on the other hand, you will remember that one of Dr. Conan Doyle's schoolmasters, in a fit of rage over his pupil's fancied stupidity, told him that he would never amount to anything.

What measures must we adopt to prevent nerve strain in school children?

1. I believe that a child should not be sent to the public schools before he is seven years of age.

2 . I should advocate separate rooms for recitation and study. Furnish a study room for the child that shall be as free as possible from all disturbing influences.

3. Compulsory examination of the eyes of all children at least once a year, all errors of refraction to be corrected by a competent oculist, furnished by the state. If a student desires to enter college, he should submit to as thorough a physical examination as that required by the United States Army or Navy, and if he falls below a certain standard, he should be discouraged from attempting to obtain a higher education.

4. A more elastic curriculum for pupils in feeble health. The need for this was forcibly brought to my attention a week or two ago in the case of a young girl who by reason of delicate health has always found the work of the school year a severe tax upon her energy and strength. Last year she was kept out of school for three months by an operation for appendicitis. Those three months she is required to make up in order to graduate, so that now she is endeavoring to do twelve months' work in nine months' time. Of course it is fair to say that she ought not to attempt to graduate, but should not the school curriculum be made up with some little allowance at least for absence and sickness? At present it seems to be based upon the utmost that a vigorous person can accomplish in a given time.

5. A most careful study of the child by both teacher and parents, to see that no more mental work is required of him than he can endure without detriment to his health. I believe most earnestly in a liberal education, but I realize also that some of us are not fitted for it. Better a generation of healthy fools than a race of wise invalids.

6. Select the best of teachers and pay them liberally. Who but a wise man can balance the mental against the physical capacity of your child and mine? When such a man is found, no mere money consideration should take him from us. It is false economy to cut down the school appropriation, for where can money be better expended than in the making and in the developing of the future statesman and yeoman, who shall be a bulwark and a defense for his state and for his nation in the time of stress, an American citizen in the fullest acceptation of the term.

December, 1908. Two years have elapsed since this paper was written and I find myself to-day firmer than ever in my conviction that something must be done to relieve the nerve strain of the student. 
Last week a gentleman said to me: " My daughter has always had an ambition to go to college. She is now in the second year of her high school course, and she declares that if she can manage to graduate from the high school she will never go any farther."

Yesterday a doctor said of his son, "A. has to work days, nights and Sundays to keep his scholarship up to the standard in the high school."

To-day a woman said to me, "My son was within three months of graduating from-College when he broke down. That was a year and a half ago and he is not able to go back yet. I doubt if he ever graduates."

To cap the whole I quote from the morning's paper.

"Yale ought to establish a guard at West Rock, the high cliff on the outskirts of New Haven. The number of students who hurl themselves from its lofty summit while laboring under temporary aberration of mind, due generally to overstudy or over-anxiety concerning their studies, is getting to be something rather startling as well as admonitory. This latest one is the fourth in a single class."

Is it wise to make school work so severe as to kill out the laudable ambition of our children? The young man who spent three years and three quarters in college undoubtedly profited thereby, but he has no diploma and is, therefore, without his ticket of admission into the great business world.

The educated man of twenty-five years ago accepted as a matter of course that his son should go to college. To-day he faces the possibility of his child being returned to him after four years a physical wreck. It is useless to argue that the percentage of breakdowns in school is relatively small. That percentage may involve your child or mine, and, moreover, it is a percentage that is alarmingly on the increase.

\section{ETHYL CHLORIDE IN GENERAL ANESTHESIA.}

BY ARTHUR M. DODGE, M.D.,

Visiting Anesthetist to St. Elizabeth's Hospital, Boston.

How to induce anesthesia in the quickest, safest and most agreeable manner is a question that is continually recurring to the surgeon and the anesthetist. What agent or agents to use, and in what sequence or combination to employ them may become a question of very great importance. The time has gone by when ether naturally was looked upon as the narcotic selected and any one (student or half-trained nurse) knew enough to administer it.

Ether is still thought of first by most physicians and, indeed, is the anesthetic found to be the most satisfactory for all but the minor and quicker operations. Ether, however, has the misfortune to be objectionable to the majority of patients in many ways; first, the odor is offensive; inhalation irritates the throat, causing choking and strangling sensations, while after-effects are most disagreeable and last for a considerable period.
Therefore, there is a demand for some other narcotic in general use where examinations and dressings of a painful nature are to be made or in the reduction of dislocations, the opening of abscesses and again in many conditions where anesthesia for only a very short period is desirable and a prolonged period of recovery can be climinated. For such cases ethyl chloride is found to be a most useful anesthetic. The anesthesia is pleasant and rapid, lasting usually from a few seconds to possibly three or four minutes, and from which recovery takes place quickly with little or no after-effect. If employed by a physician in his office the patient in half an hour can walk out as if no anesthetic had been administered Another and very important factor is the ethyl chloride-ether sequence, given as an introduction to ether where anesthesia is desired for a more or less prolonged period. One advantage of this procedure is the great relief to the sensibilities of the patient. Many persons insist that they dread the taking of ether more than anything else. Other desirable points gained aré: (a) reduction of time necessary to induce narcosis, (b) abolishment in most cases of the stage of muscular excitement, (c) a decrease in the amount of ether inhaled and $(d)$ the tendency to lessen the usual after-effects of anesthesia.

Ethyl chloride was known as an anesthetic before 1850 , but was little used until about 1900 . In 1880 a committee of the British Medical Society reported that ethyl chloride was not safe to use as a general anesthetic owing to its liability to cause respiratory failure and convulsions. Even as late as 1898, in Sajous' Annual, the state ment is made, "We would also warn against its [ethyl chloride] use for the purpose of inducing general anesthesia, as the dangers incurred therefrom are too great." Interest in its use was revived at this time (1898) by the reports of Lotheisen, and in 1901 by McCardie, who reported a large number of successful cases in general anesthesia. It is believed that the bad results obtained earlier were due partly to impure preparation of the drug, as well as improper methods of administration. The purity of ethyl chloride may be roughly tested by the absence of any disagreeable or garlicky odor and also by the fact that it should not turn blue litmus paper red. It is easily tested by pouring a little into the palm of the hand, and, if pure, no objectionable odor can be detected on evaporation.

Ethyl chloride may be given in almost as large a variety of ways as ether: by means of a closed inhaler, in a semi-open mask, or poured on gauze held in the palm of the hand. This last is convenient and satisfactory in confinements, while the first or closed method is perhaps the best for examinations and short operations. In the ethyl chloride-ether sequence the writer prefers the semi-open method, the distinction being chiefly in the amount of air allowed to mix with the anesthetic. The dangers of interference with respiration and circulation are often caused by using too concentrated a vapor and are greatly lessened by admitting a large amount of air. 